\title{
ANALISIS PERUBAHAN SIFAT MEKANIS TANAH GAMBUT PADA STABILISASI TANAH SECARA KIMIAWI MENGGUNAKAN DIFASOIL STABILIZER DAN SEMEN
}

\author{
Yusuf Amran ${ }^{1}$, Iwan Permadi ${ }^{2}$ \\ Program Studi Teknik Sipil Universitas Muhammadiyah Metro, ${ }^{1,2}$ \\ E-mail :yusufamran307@gmail.com¹, iwanpermadi15@gmail.com²
}

\begin{abstract}
ABSTRAK
Tanah gambut merupakan tanah yang mengandung bahan organik dalam jumlah yang besar. Kandungan organik didapat dari sisa penimbunan dan pembusukan tumbuhan yang belum selesai, namun berlangsung dalam waktu yang lama. Tanah gambut memiliki angka pori dan kadar air yang sangat tinggi. Dalam pekerasan jalan, subgrade atau tanah dasar merupakan bagian yang sangat penting . Letaknya yang berada di bagian paling dasar menjadi lapisan ini sangat berperan besar dalam konstruksi pekerasan . Meskipun demikian, dengan berbagai alasan dan pertimbangan pekerjaan konstruksi diatas tanah gambut sering terpaksa dilakukan, terutama untuk pembangunan di daerah pemukiman dan jalur jalan raya seperti yang ada di daerah Sumatera, Kalimantan, dan Papua. Salah satu cara stabilisasi adalah dengan cara kimiawi yakni dengan menggunakan bahan campuran zatadditive berupa Difa Soil Stabilizer.Difa Soil Stabilizermerupakan bahan additive yang berfungsi memadatkan (solidifikasi) dan menstabilkan (stabilizer). Prinsip kerja komponen difa soil stabilizer adalah dengan menyisihkan mineral yang berada pada permukaan partikel tanah. Sedangkan bahan semen (soil cemen) ini berfungsi sebagai perekat yang mengikat fragmen-fragmen mineral menjadi satu kesatuam yang homogeny. Pelaksanaan pengujian dilakukan di Laboratorium Mekanika Tanah Jurusan Teknik Sipil, Universitas Muhammadiyah Metro, Lampung. Pengujian yang dilakukan dibagi menjadi 2 bagian pengujian yaitu pengujian untuk tanah asli dan tanah yang telah distabilisasi, adapun pengujian-pengujian tersebut adalah pengujian sampel tanah asli meliputi Pengujian Uji Kadar Air, Pengujian Uji Analisis Saringan, Pengujian Uji Batas Atteberg Limit, Pengujian Uji Berat Jenis, Pengujian Pemadatan Tanah (proctor), Pengujian Kuat Geser sedangkan Pengujian pada tanah gambut yang telah distabilisasi dengan Difa Soil Stabilizer dan semen meliputi Pengujian Pemadatan Tanah (proctor) dan Pengujian Kuat Geser tanah.

Berdasarkan hasil penelitian yang dilakukan dapat disimpulkan bahwa sampel tanah yang diberi penambahan difa soil stabilizer dapat memperbaiki atau meningkatkan daya dukung sifat mekanis tanah. Nilai PI semakin menurun dan tingkat kepadatan semakin meningkat namun nilai kuat geser tanah berkurang. Untuk pengujian kuat geser tanah yang dilakukan di Laboratorium Teknik Sipil Universitas Muhammadiyah Metro, dari ke empat sampel yang telah diujikan dengan campuran difa soil stabilizer yakni 0,2\%, 0,4\%, 0,6\%, 0,8\% + $8 \%$ semen dalam setiap pengujian kuat geser campuran. Dari ke empat pengujian nilai tegangan geser dengan campuran $0,4 \%$ difa soil stabilizer $+8 \%$ semen mendapat kadar campuran dengan nilai lebih maksimum yakni mendapatkan nilai kohesi $0,13 \mathrm{~kg} / \mathrm{cm}^{2}$, sedangkan untuk sudut geser dalam mendapatkan nilai $36,82^{\circ}$.
\end{abstract}

Kata Kunci: Stabilisasi, Tanah Gambut, Kimiawi 


\section{PENDAHULUAN}

Dalam pengertian teknik secara umum, tanah didenifisikan sebagai material yang terdiri dari agregat (butiran) mineral-mineral padat yang tidak tersementasikan (terikat secara kimia) satu sama lain dari bahan-bahan organik yang telah melapuk (yang berpatikel padat), yang disertai zat cair dan gas yang mengisi ruang-ruang kosong diantara partikel-partikel padat tersebut (Bambang Surendro, 2015:2) . Tanah berguna sebagai bahan bangunan pada berbagai macam pekerjaan teknik sipil, disamping itu tanah berfungsi untuk mendukung suatu kontruksi teknik sipil seperti pondasi bangunan dan pekerjaan pekerasan jalan.

Tanah gambut merupakan tanah yang mengandungbahan organik dalam jumlah yang besar. Kandungan organik didapat dari sisa penimbunan dan pembusukan tumbuhan yang belum selesai, namun berlangsung dalam waktu yang lama. Tanah gambut memiliki angka pori dan kadar air yang sangat tinggi. Dalam pekerasan jalan, subgradeatau tanah dasar merupakan bagian yang sangat penting. Letaknya yang berada di bagian paling dasar menjadi lapisan ini sangat berperan besar dalam konstruksi pekerasan . Meskipun demikian, dengan berbagai alasan dan pertimbangan pekerjaan konstruksi diatas tanah gambut sering terpaksa dilakukan, terutama untuk pembangunan di daerah pemukiman dan jalur jalan raya seperti yang ada di daerah Sumatra, Kalimantan, dan Papua. Untuk itu diperlukan perbaikan agar dapat mendukung beban besar. Metode yang digunakan dalam perbaikan tersebut adalah dengan stabilisasi .

Stabilisasi merupakan upaya untuk memperbaiki sifat dan parameter dari tanah asli agar tanah tersebut sesuai atau memenuhi syarat untuk dipergunakan sesuai fungsinya. Penambahan bahan campuran dalam stabilisai tanah telah lama dikembangkan karena dengan stabilisasi dengan cara ini memiliki keunggulan jika dibandingkan dengan mengganti material baru yaitu lebih ekonomis.Sedangkan stabilisasi secara kimiawi dilakukan dengan memperbaiki gaya ikatan secara mikro antara butir tanah dan bahan pembantu.

Salah satu cara stabilisasi adalah dengan cara kimiawi yakni dengan menggunakan bahan campuran zatadditive berupa Difa Soil Stabilizer.Difa Soil Stabilizermerupakan bahan additive yang berfungsi memadatkan (solidifikasi) dan menstabilkan (stabilizer). Prinsip kerja komponen difa soil stabilizer adalah dengan menyisihkan mineral yang berada pada permukaan partikel tanah. Sedangkan bahan semen (soil cemen) ini berfungsi sebagai perekat yang mengikat fragmen-fragmen mineral menjadi satu kesatuam yang homogen

Uji kuat geser tanah untuk menentukan kuat geser tanah dan susut geser dalam tanah. Uji kuat ini mengukur seberapa kuat tanah menerima kuat tekan yang diberikan sampai tanah tersebut terpisah dari butiran-butirannya juga mengukur regangan tanah akibat tekanan tersebut.

\section{TINJAUAN PUSTAKA}

\section{Pengertian Umum Tanah}

Tanah adalah material yang terdiri dari butiran menerial-meniral padat yang tidak terikat secara kimia satu sama lain dan dari bahan-bahan organik yang telah melapuk disertai dengan zat cair dan gas yang mingisi ruang-ruang kosong diantara partikel-partikel padat tersebut (Das, 1988). Selain itu dalam arti lain tanah merupakan akumulasi partikel meneral atau ikatan antar partikelnya, yang terbentuk karena pelapukan dari batuan (Craig, 1991) . Tanah juga didefinisikan sebagai akumulasi partikel mineral yang tidak mempunyai atau 
lemah ikatan partikelnya, yang terbentuk karena pelapukan dari batuan

Diantara partikel-partikel tanah terdapat ruang kosong yang disebut poripori yang berisi air dan udara. Ikatan yang lemah antara partikel-partikel tanah disebabkan oleh pengaruh karbonat atau oksida yang tersenyawa diantara partikelpartikel tersebut, atau dapat juga disebabkan oleh adanya material organik bila hasil dari pelapukan tersebut diatas tetap berada pada tempat semula maka bagian ini disebut tanah sisa (residu soil). Hasil pelapukan terangkut ke tempat lain dan mengedap di beberapa tempat yang berlainan disebut tanah bawah (transportationn soil) . Media pengakutan tanah berupa gravitasi, angin, air dan gletsyer. Pada saat akan berpindah tempat, ukuran dan bentuk partikel-partikel dapat berubah dan berbagi dalam beberapa rentang ukuran.

\section{Klasifikasi Tanah}

Sistem klasifikasi tanah adalah suatu sistem atau cara pengelompokan tanah berdasarkan sifat dan ciri tanah yang sama atau hampir sama, kemudian diberi nama agar mudah dikenal, diingat, dan dibedakan dengan tanah-tanah lainnya. Tujuan klasifikasi tanah adalah untuk menentukan kesesuaian terhadap pemakaian tertentu, serta untuk menginformasikan tentang keadaan tanah dari suatu daerah kepada daerah lainnya dalam bentuk berupa data dasar. Klasifikasi bermaksud membagi tanah menjadi beberapa golongan tanah dengan kondisi dan sifat yang serupa diberi simbol nama yang sama.

Terdapat dua sistem klasifikasi yang sering digunakan, yaitu USCS (Unified Soil Classification System) dan AASHTO (American Association of State Highway and Transportation Officials). Sistem-sistem ini menggunakan sifat-sifat indeks tanah yang sederhana seperti distribusi ukuran butiran, batas cair dan indeks plastisitas.

\section{Tanah Gambut}

Tanah gambut mempunyai ciri yang khas yaitu mengandung serat-serat organik tinggi, berwarna coklat sampai hitam (ASTM D2488). Tanah gambut merupakan campuran fragmen organik, berasal dari vegestasi yang telah berubah dan memfosil secara kimiawi . Terlihat secara mendetail struktur mikro dengan ruang pori besar sehingga dapat dimengerti bahwa kandungan air dan kompresibilitas tanah tersebut tinggi. Gambut yang berada di bawah permukaan mempunyai daya mampat yang tinggi dibandingkan dengan mineral tanah pada umumnya . Istilah tanah gambut hanya berhubungan dengan bahan organik berasal dari proses geologi selain batubara. Tanah gambut terbentuk dari tumbuh-tumbuhan yang telah mati, berada didalam air dan hampir tidak ada udara didalamnya, terjadi dirawa-rawa dan mempunyai kadar abu tidak lebih dari $25 \%$ berat kering, dengan demikian rawa merupakan tempat pembentukan tanah gambut, dipengaruhi oleh iklim, hujan, pristiwa pasang surut, jenis vegetasi rawa, topografi serta beberapa aspek geologi serta hidrologi daerah setempat (ASTM D2607)

Proses pembentukan tanah gambut dimulai dari adanya pendangkalan danau yang secara perlahan ditumbuhi oleh tanaman air dan vegetasi lahan basah (Noor, 2001). Tanaman yang mati dan melapuk, secara bertahap membentuk lapisan yang kemudian menjadi lapisan transisi antara lapisan gambut dengan substrantum (lapisan dibawahnya) berupa tanah meniral. Tanaman berikutnya tumbuh pada bagian yang lebih tengah dari danau dangkal ini dan secara bertahap membentuk lapisan-lapisan gambut, sehingga danau tersbut menjadi penuh. Bagian gambut yang tumbhuh mengisi danau dangkal tersebut dikenal sebagai gambut topogen, karena proses pembentukannya desebabkan oleh topografi oleh daerah cekung. 


\section{Stabilisasi Tanah}

Stabilisasi tanah adalah usaha untuk merubah atau memperbaiki sifat-sifat teknis tanah dengan menambahkan sesuatu pada tanah tersebut, agar dapat menaikkan kekuatan tanah dan mempertahankan kekuatan geser. Adapun tujuan stabilisasi tanah adalah untuk mengikat dan menyatukan agregat material yang ada sehingga sifat teknis tanah menjadi lebih baik. Sifat-sifat tanah yang dapat diperbaiki dengan cara stabilisasi dapat meliputi : kestabilan volume, kekuatan atau daya dukung, permeabilitas, dan kekekalan atau keawetan.

Menurut Bowles, 1991 beberapa tindakan yang dilakukan untuk menstabilisasikan tanah adalah sebagai berikut :

a. Meningkatkan kerapatan tanah.

b. Menambah material yang tidak aktif sehingga meningkatkan kohesi dan/atau tahanan gesek yang timbul.

c. Menambah bahan yang menyebabkan perubahan kimiawi dan fisis tanah.

d. Menurunkan muka air tanah (drainase tanah).

e. Mengganti tanah yang buruk.

\section{Tipe-Tipe Stabilisasi}

Pada umumnya tipe atau cara yang digunakan untuk stabilisasi tanah dapat dibagi menjadi tiga yaitu :

a. Stabilisasi Alami

Stabilisasi alami merupakan jenis stabilisasi yang terjadi karena proses alam sehingga tidak membutuhkan perlakuan khusus dalam memperbaiki sifat mekanis tanah. Contoh tanah memadat akibat berat sendiri, resapan air hujan, penyusutan air akibat penguapan, akar tanaman dan lainlain.

b. Stabilisasi Mekanis

Stabilisasi mekanis atau mekanikal dilakukan dengan cara mencampur atau mengaduk dua macam tanah yang bergradasi berbeda secara proporsional yang diikuti dengan proses pemadatan, untuk mendapatkan kepadatan maksimum. Stabilisasi mekanis juga dapat dilakukan dengan cara menggali tanah buruk ditempat dan menggantinya dengan material granular dari tempat lain. Menurut Lambe (1962) stabilisasi mekanis merupakan suatu proses yang menyangkut dua cara perubahan sifatsifat tanah :

1. Penyusunan kembali partikel tanah, seperti contohnya pencampuran beberapa lapisan tanah, pembentukan kembali tanah yang telah terganggu dan pemadatan.

2. Penambahan atau penyingkiran partikel tanah. Contohnya lempung berpasir dicampur dengan kerikil untuk memenuhi daya dukung di jalan tertentu.

c. Stabilisasi Kimiawi

Stabilisasi dengan bahan tambah atau dapat disebut juga stabilisasi kimiawi yaitu stabilisasi menggunakan bahan kimia untuk memungkinkan terjadinya reaksi kimia, dan menghasilkan senyawa baru yang bersifat stabil. bertujuan untuk memperbaiki sifat-sifat teknis tanah. Metode ini dapat menggunakan larutan kimia/bubuk kimia, yang dicampurkan dengan tanah yang akan diperbaiki, dengan beberapa metode pencampuran yang disesuaikan dengan kondisi bahan pencampur maupun kondisi tanahnya. . Contoh : Kapur, semen portland, abu terbang (fly ash) aspal dan lain-lain.

\section{Difa Soil Stabilizer}

Difa soil stabilizer adalah bahan additive yang berfungsi untuk memadatkan (solidifikasi) dan menstabilkan (stabilizer) tanah secara fisik-kimia yang berupa material serbuk halus yang terdiri dari komposisi mineral anorganik. Stabilisasi dengan menggunkan bahan tambahan atau sering 
disebut juga stabilisasi kimiawi bertujuan untuk memperbaiki sifat-sifat teknis tanah, dengan cara mencampur tanah dengan penggunanan bahan tambahan dengan komposisi perbandingan yang sudah ditetapkan . Jika percampuran hanya dimaksudkan hanya untuk mengubah gradasi dan plasitas tanah, dan kemudian dikerjakan, maka hanya diperlukan penambahan zat additive yang sedikit. Namun stabilisasi dimaksudkan untuk merubah tanah agar mempunyai kekuatan tinggi, maka diperlukan bahan pencampuran zat additive ini harus dihampar dan disimpan ditempat yang baik supaya mendapat nilai yang diinginkan .

Difa soil stabilizer adalah salah satu stabisasi kimiawi dengan cara ion exchange, produk ini dikembangkan PT. DIFA MAHA KARYA yang beralamatkan Jl. Kaliurang KM.13, RT 04/RW 09, No.120, Dusun Wonosalam, Desa Sukaharj, Ngagli Sleman 55581, Yogyakarta.

Soil stabilizer adalah metode perbaikan tanah untuk dapat memenuhi spesifikasi teknis material dalam aplikasi teknik stbalisasi tanah dapat dilakuakan secara mekanis dan kimiawi. Stabilisasi secara mekanis adalah dengan memperbaiki sifat tanah secara fisik, biasanya dilakukan dengan mengurangi volume rongga udara pada kadar air yang optimum saat pemadatan (compoction) dilakuakan. Sedangkan stabilisasi secara kimiawi dilakuakan dengan memperbaiki gaya ikatan secara mikro antara butir tanah dan bahan pembantu yaitu difa soil stabilizer.

\section{Semen}

Semen merupakan bubuk halus yang bila dicampur dengan air akan menjadi ikatan yang akan mengeras, karena terjadi reaksi kimia sehingga membentuk suatu massa yang kuat dan keras . Reaksi-reaksi tersebut menghasilkan bermacam-macam senyawa kimia yang menyebabkan terjadinya pengerasan .
Semen (portland cement) di definisikan sebagai suatu hasil produk yang terdiri dari sebagian besar kalsium silikat yang didapat dari pemanasan hingga meleburnya campuran homogen, bahan yang utamanya berisikan kapur $\left(\mathrm{C}_{\mathrm{a}} \mathrm{O}\right)$ dan silikat $\left(\mathrm{SiO}_{2}\right)$ dengan jumlah kecil alumunia $\left(\mathrm{Al}_{2} \mathrm{O}_{3}\right)$ dan besi oksida $\left(\mathrm{F}_{\mathrm{e} 2} \mathrm{O}_{3}\right)$.

\section{Pengujian Sifat Mekanis Tanah}

Stabilisasi mekanis atau stabilisasi mekanikal dilakukan dengan mencampur atau mengaduk dua macam tanah atau lebih yang bergradasi berbeda untuk memperoleh material yang memenuhi syarat yang telah ditentukan komposisi tambahannya. Pencampuran tanah ini dapat dilakukan dilokasi proyek atau di laboratorium, dipabrik, atau dilakukan di tempat pengambilan bahan timbunan (borrow area) tetapi penelitian ini dilakukan di labratorium Teknik Sipil Universitas Muhammadiyah Metro, Lampung. Material yang telah dicampur ini, kemudian dihamparkan dan dipadatkan di laboratorium. Stabilisasi mekanis juga dapat dilakukan dengan cara mengambil tanah langsung ditempat dan menggantinya dengan material granuler ditempat lain .

Menurut lambe (1962), dan Hary Cristady Hardiyatmo (2010), stabilisasi mekanis merupakan suatu proses yang menyangkut dua cara perubahan sifat sifat tanah :

a. Penyusunan kembali partikel partikel tanah, seperti contohnya pencampuran beberapa lapisan tanah, pembentukan kembali tanah yang telah terganggu dan pemadatan.

b. Penambahan atau penyingkiran partikel-partikel tanah, sifat fisik tanah tertentu dapat diubah dengan menambahkan dan memisahkan ini umumnya sangat lebih rendah dibandingkan dengan metode stabilisasi yang lain. 


\section{METODE PENELITIAN}

\section{Lokasi Penelitian}

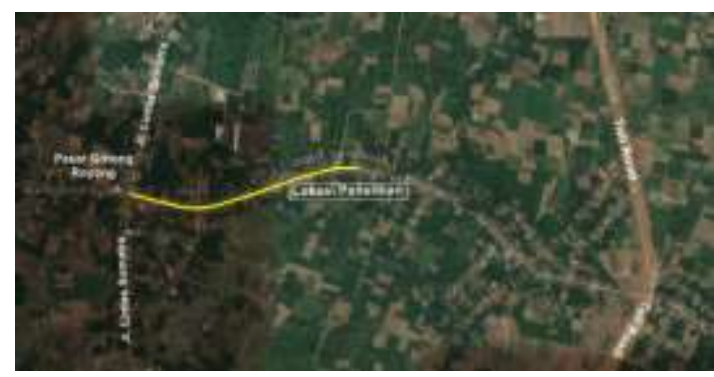

Gambar 1. Lokasi Penelitian

\section{Teknik Sampling}

Metode pecampuran sampel tanah, metode pecampuran untuk masingmasing prosentasi dicampur dengan sampel tanah yang lolos saringan No.4 $(4,75 \mathrm{~mm})$ adalah penambahan bahan Difa Soil Stabilizer dan Semen dilakukan dengan cara coba-coba (trial and eror) terhadap masing masing sampel tanah asli untuk mendapatkan persentase kadar terbaik hingga didapatkan niali yang di inginkan.

1) Kebutuhan campuran tanah asli, Difa Soil Stabilizer dan Semen pada pengujian pemadatan (modifiet) :

Contoh perhitungan kebutuhan 1 sampel pengujian pemadatan (modifiet) :

Tanah awal/lepas $=5000$ gram

$$
\begin{gathered}
\frac{0,2}{100} \times 5000=10 \text { gram Difa Soil } \\
\frac{8}{100} \times 5000=400 \text { gram Semen } \\
\frac{100 \mathrm{ml}}{5000} \times 100=2 \% \text { Air }
\end{gathered}
$$

Tabel 1. Contoh Sampel 1 Pengujian Pemadatan Proctor Modified

\begin{tabular}{cccc}
\hline $\begin{array}{c}\text { Sampel tanah } \\
\text { awal/lepas }\end{array}$ & $\begin{array}{c}\text { Difa } \\
\text { SS }\end{array}$ & Semen & Air \\
\hline 5000 gr & $0,2 \%$ & $8 \%$ & $\begin{array}{c}100 \\
\mathrm{ml}\end{array}$ \\
$5000 \mathrm{gr}$ & $0,2 \%$ & $8 \%$ & $\begin{array}{c}200 \\
\mathrm{ml}\end{array}$ \\
& & & 300 \\
$5000 \mathrm{gr}$ & $0,2 \%$ & $8 \%$ & $\mathrm{ml}$ \\
& & & 400 \\
$5000 \mathrm{gr}$ & $0,2 \%$ & $8 \%$ & $\mathrm{ml}$ \\
$5000 \mathrm{gr}$ & $0,2 \%$ & $8 \%$ & $\begin{array}{c}500 \\
\mathrm{ml}\end{array}$ \\
\hline
\end{tabular}

Catatan : Penambahan kadar air pada sampel pengujian kuat geser didapat dari penambahan kadar air optimum pengujian sampel uji pemadatan proctor modified.

2) Kebutuhan sampel tanah pengujian kuat geser tidak ditentukan beratnya hanaya menyesuaikan dengan cetakan. Pada pengujian ini yang digunakan pengujian kuat geser yakni menggunakan kadar optimum (OMC) pada pengujian proctor modified.

\section{Peralatan}

Peralatan yang digunakan dalam penelitian ini adalah alat untuk uji proctor modified, uji kuat geser, uji analisa saringan, uji kadar air, dan uji berat jenis dan uji atterbeg limit yang ada di Laboratorium Mekanika Tanah Prodi Teknik Sipil, Universitas Muhammadiyah Metro yang telah sesuai Standarisasi American Society For TestingMaterial (ASTM) .

\section{Bahan Penelitian}

Bahan uji yang dipakai dalam penelitian ini adalah sebagai berikut :

1) Sampel tanah yang berupa tanah gambut yang berasal dari Desa Cabang, Kecamatan Bandar Surabaya, Kabupaten Lampug Tengah .

2) Air yang berasal dari Laboratorium Mekanika Tanah Fakultah Teknik Universitas Muhammadiyah Metro Lampung .

3) Difa Soil Stabilizer sebagai media stabilisasi dan pemadatan tanah berasal dari PT. DIFA MAHA KARYA, Yogyakarta .

4) Semen yang digunakan sebagai bahan penelitian ini adalah PCC tipe 1 diperoleh dari toko bangunan.

\section{Prosedur Pengujian Penelitian}

Pelaksanaan pengujian dilakukan diLaboratorium Mekanika Tanah Fakultas Teknik Jurusan Teknik Sipil Universitas Muhammadiyah Metro. 
Pengujian yang dilakukan dibagi menjadi 2 bagian pengujian yaitu pengujian untuk tanah asli dan tanah yang telah distabilisasi, adapun pengujian-pengujian tersebut adalah sebagai berikut :

A. Pengujian sifat fisik tanah / properti tanah gambut, meliputi :

Tanah Asli

1. Uji Analisis Saringan

2. Uji Kadar Air

3. Uji Berat Jenis

4. Uji Batas-Batas Atterberg

B. Pengujian sifat mekanis tanah gambut asli dan campuran, meliputi:

1. Uji Pemadatan tanah / Uji Proctor (Modified).

2. Uji Kuat Geser Tanah.

\section{Tahapan Penelitian}

Tahapan/urutan prosedur pada penelitian ini meliputi :

1. Hasil dari pengujian sampel tanah asli $(0 \%)$ yang ditampilkan dalam bentuk tabel dan digolongkan berdasarkan sistem klasifikasi tanah AASHTO.

2. Dari hasil pengujian sampel tanah asli seperti uji analisa saringan, uji berat jenis, uji kadar air, uji batas Atterberg, uji pemadatan tanah, dan uji DS, ditampilkan dalam bentuk tabel dan grafik yang nantinya akan didapatkan nilai/data sebagai berikut:

Tabel 2. Pengujian Sampel Tanah

\begin{tabular}{|c|c|c|}
\hline No. & Data Pengujian Tanah & Hasil \\
\hline 1. & \multicolumn{2}{|l|}{ Analisis Saringan } \\
\hline & Lolos saringan no. 200 & $\%$ \\
\hline 2. & $\operatorname{Kadar} \operatorname{Air}(\mathrm{W})$ & $\%$ \\
\hline 3. & Berat Jenis (Gs) & \\
\hline 4. & \multicolumn{2}{|l|}{ Batas-Batas Atterberg } \\
\hline & Batas Cair (LL) & $\%$ \\
\hline & Batas Plastis (PL) & $\%$ \\
\hline & Indeks Plastisitas (PL) & $\%$ \\
\hline 5. & \multicolumn{2}{|c|}{ Pemadatan Tanah / Proctor } \\
\hline & Berat isi kering $\left(\gamma d_{\max }\right)$ & $\mathrm{gr} / \mathrm{cm}^{3}$ \\
\hline & OMC & $\%$ \\
\hline 6. & Kuat Geser Tanah/DS & $\begin{array}{l}S, \sigma, \\
\varphi_{\mathrm{u},} \mathrm{c}_{\mathrm{u}}\end{array}$ \\
\hline
\end{tabular}

Sumber: Standarisasi pengujian tanah laboratorium

\section{Analisis Hasil Penelitian}

Semua hasil yang didapat dari pelaksanaan penelitian akan ditampilkan bentuk tabel, grafik hubungan serta penjelasan-penjelasan yang didapat dari :

1. Hasil dari pengujian sampel tanah asli yang ditampilkan dalam bentuk tabel dan digolongkan berdasarkan sistem klasifikasi tanah USCS dan sistem klasifikasi metode SNI

2. Dari hasil pengujian sampel tanah asli terhadap masing-masing pengujian seperti uji kadar air, uji berat jenis, uji analisa saringan, uji atterberg limit, uji pemadatan tanah dan uji kuat geser tanah ditampilkan dalam bentuk tabel dan grafik yang nantinya akan didapatkan kadar air kondisi optimum .

3. Dari hasil pengujian kuat geser terhadap masing-masing variasi campuran kadar semen dan difa soil stabilizer setelah waktu pemeraman selama 24 jam ditampilkan dalam bentuk tabel dan grafik .

4. Analisis mengenai perubahan karakteristik pada pencapuran difa soil stabilizer dengan sampel tanah gambut setelah pemeraman 24 jam dengan mengacu pada perubahan nilai dari parameter-parameter pengujian seperti pengujian kuat geser, pengujian atterberg limit dan pengujian berat jenis, sebagai berikut :

a. Dari hasil pengujian berat jenis didapatkan hasil pengujian yang ditampilkan dalam bentuk tabel dan grafik. Dari tabel dan grafik nilai berat jenis tersebut maka akan didapatkan penjelasan perbandingan antara pengaruh masing-masing kadar semen dan difa soil stabilizer terhadap nilai berat jenisnya.

b. Dari hasil pengujian laboratorium untuk parameter batas-batas konsistensi yang terdiri dari 3 
parameter yaitu batas plastis (PL), batas cair (LL), dan indeks plastisitas (PI), yang kemudian dipaparkan hasilnya bentuk tabel dan grafik. Dari tabel dan grafik nilai batas cair dan batas plastis tersebut maka akan didapatkan penjelasan perbandingan antara pengaruh masing-masing kadar semen dan difa soil stabilizer dengan nilai batas batas cair dan batas plastisnya.

c. Hasil pengujian paramater kuat geser, nilai kekuatan daya dukung campuran akan ditampilkan dalam bentuk tabel dan grafik hubungan antara nilai peningkatan atau penurunan nilai kuat geser dalam kondisi pemeraman selama 24 jam. Dari tabel dan grafik nilai kuat gesertersebut maka akan didapatkan penjelasan mengenai perbandingan kualitas daya dukung tanah yang terjadi pada masingmasing variasi campuran.

Dari seluruh analisis hasil penelitian tersebut, maka akan ditarik kesimpulan berdasarkantabel dan grafik yang telah ada terhadap hasil penelitian yang didapat.

\section{HASIL PENELITIAN}

\section{Rekapitulasi Hasil Pengujian Tanah Asli 0\%}

Tabel 3. Rekapitulasi Hasil Pengujian Tanah Asli

\begin{tabular}{|c|c|c|}
\hline \multirow{3}{*}{$\frac{\text { No }}{1 .}$} & Pengujian & Hasil \\
\hline & Analisa Saringan & \\
\hline & $\begin{array}{l}\text { Lolos Saringan No.200 } \\
(\%)\end{array}$ & $0,82 \%$ \\
\hline 2. & Kadar Air (w) & $73,79 \%$ \\
\hline 3. & Berat Jenis (Gs) & $\begin{array}{l}1,73 \% \\
\mathrm{gr} / \mathrm{cm}^{3}\end{array}$ \\
\hline 4. & Batas Atterbeg & \\
\hline & a. Batas Cair (LL) & $26 \%$ \\
\hline & b. Batas Plastis (PL) & $19,36 \%$ \\
\hline & $\begin{array}{l}\text { c. Indeks Plastisitas } \\
\text { (IP) }\end{array}$ & $6,64 \%$ \\
\hline 5. & Pemadatan (Modified) & \\
\hline & a. Kadar Air Optium & $29,50 \%$ \\
\hline
\end{tabular}

\begin{tabular}{ccc}
\hline \multicolumn{3}{c}{ (OMC) } \\
\hline $\begin{array}{c}\text { b. Berat Isi Kering } \\
\text { Maksimum }\left(\gamma_{\text {dmaks }}\right)\end{array}$ & $\begin{array}{c}1,21 \% \\
\text { gr/cm }\end{array}$ \\
\hline 6. & Nilai Kuat Geser & $0,14^{\circ}$ \\
\hline (Hasil Pengujian Di Laboratorium, 2021)
\end{tabular}

\section{Kesimpulan Pengujian Menurut USCS dan AASTHO}

Dari hasil pengujian sifat fisik dan mekanis tanah asli pada tabel, diatas dapat diguankan untuk mengetahui massa penurunan tanah yang telah dilakukan penelitian dari hasil klasifikasi tanah menurut USCS dan AASTHO.

Menurut sistem klasifikasi USCS, hasil pengujian sifat fisik tanah asli menunjukan bahwa tanah tersebut memiliki nilai batas cair (LL) ratarata $26 \%(<50 \%)$, dan nilai indeks plastisitas rata-rata sebesar $6,64 \%$. Apabila nilai tersebut diplotkan pada diagram plastisitas maka tanah tersebut dalam kelompok OL yaitu lanau organis dengan plastisitas rendah dan lempung organis .

Menurut sistem klasifikasi AASHTO, persentase lolos saringan No. 200 adalah $0,00 \%$ secara umum tanah termasuk kelompok lanau. Hasil pengujian batas cair (LL) adalah $26 \%$ ( $\geq$ $41 \%$ ), nilai indeks plastisitas (PI) adalah $19,36 \%, \quad(\geq 11 \%)$. Selanjutnya jika ditinjau dari rumus PI > $30(19,36>26)$ maka tanah termasuk kelompok A6-A7. Tanah ini termasuk dengan penilaian biasa samapai buruk.

\section{Analisis Data Penelitian}

Metode analisis data adalah metode atau cara yang digunakan untuk menyederhanakan dan mempermudah dalam memahami data yang diperoleh di laboratorium. Data di laboratorium yang telah didapatkan kemudian dianalisis berdasarkan urutan pekerjaannya. Analisa data untuk mengetahui parameter tanah selama dalam penelitian serta mencari nilai-nilai komulatif tanah serta membuat kesimpuan dari hasil pengujian 
dilakukan. Berikut ini analisis terhadap data yang telah diujikan :

\section{a. Analisa Saringan Sievie Analysis (SNI-1968-1990)}

Pengujian ini bertujuan untuk menganalisis persentase ukuran butir tanah pada benda uji yang tertahan disaringan no. 200 dan untuk mengetahui pembagian butir-butir tanah (gradasi) agregat halus dan kasar dengan menggunakan saringan nomor, No.4, No.10, No.20, No.30, No.40, No.60, No.80, N0.100, N0.200 pan dan penutup. Dari hasil pengujian analisa saringan persentase lolos saringan No.4 sebesar $94,95 \%$, sedangkan persentase lolos saringan No.200 sebesar 0,82\%, dari hasil pengujian analisa saringan grafik mengalami kenaikan yang sangat signifikan. Dari pengujian analisa saringan dapat diklasifikasikan tanah yang lolos saringan No.4 termasuk kedalam kelompok tanah berbutir kasar, karena kandungan butiran yang lolos saringan No.200<50\%. (Klasifikasi USCS).

b. Pengujian Kadar Air (SNI 03-19971990)

Tujuan pengujian ini dilakukan untuk mengetahui nilai kadar air dalam tanah. Kadar air suatu tanah adalah perbandingan antara berat air yang terkandung dalam tanah dengan berat butir tanah tersebut dan dinyatakan dalam persendengan menggunakan alat oven, pengujian kadar air tanah asli pada semua titik sampel menunjukan nilai kadar air yang terkandung dalam tanah gambut tersebut sebesar 76,62\%, 77,20\%, $68,98 \%, 72,92 \%, 73,24 \%$ untuk masingmasing titik. Jika ditarik rata-rata dari semua titik sampel diperoleh kadar air dengan nilai $73,79 \%$. Hasil penelitian ini menunjukaan kandungan air dari tanah gambut yang tinggi dan memiliki nilai indeks yang tinggi (Hardiyatmo,2002).

c. Pengujian Batas Atterbeg Limit (ASTM-4318-89)

Pengujian ini bertujuan untuk menentukan batas cair tanah. Batas cair tanah adalah kadar air tanah pada keadaan batas cair dan plastis,sedangkan batas plastis adalah kadara air minimum suatu tanah dalam keadaan plastisitas. Nilai indeks plasitas (PL) sangat menentukan sifat keplastisan tanah. Semakin besar nialai $\mathrm{Pl}$, maka akan semakin besar tingkat plastis tanah tersebut. Pengamatan diperoleh nilai indeks plastisitas rata-rata sebesar $19,36 \%$, karena dilihat dari tabel sifat nilai indek plastisitas dari pengujian ini termasuk kedalam kelompok tanah yang memiliki nilai Pl $<17$ yang bersifat plastisitas tinggi dilihat dari klasifikasi tanah (Hardiyatmo,2002).

d. Pemadatan Tanah Proctor Standard(SNI 03-1744-2012)

Pengujian ini untuk menentukan hubungan kadar air dan berat volume, dan untuk mengevaluasi tanah agar memenuhi persyaratan kepadatan. Untuk berbagai jenis tanah pada umumnya, terdapat satu nilai kadar air optimum tertentu untuk mencapai berat volume kering maksimumnya dengan alat yang digunakan satu set uji proctor. Hasil dari pengujian pemadatan diperoleh nilai OMC dan ${ }^{x_{\text {dmaks }}}$ dari hasil kadar campuran bahan additive difa soil stabilizer mendapatkan kadar campuran maksimum $0,8 \%$ dengan kadar air optimum $38,20 \%$, dengan berat kering maksimum 1,15 gr/ $\mathrm{cm}^{3}$. Menurut Proctor (1933) dan Hardiyatmo (2002), hubungan yang pasti antara kadar air dan berat volume, karena hal ini air mengisi rongga pori yang sebelumnya di isi oleh butiran padat setelah dilakukan pemadatan dengan penambahan campuran zat additive tanah akan mencapai batas maksimum.

e. Pengujian Berat Jenis SNI 19642008

Tujuan pengujian berat jenis tanah untuk mendapatkan nilai berat jenis dari suatu sampel tanah. Berat jenis tanah adalah perbandingan antara berat volume butiran padat dengan berat volume air pada temperatur tertentu. Sampel tanah 
asli yang lolos saringan No.40 dikeringkan dalam oven. Didapatkan berat jenis (Gs) rata-rata per titik antara $1,73 \mathrm{gr} / \mathrm{cm}^{3}$. Jika diambil rata-rata dari semua titik diperoleh nilai berat jenis (Gs) 1,73 $\mathrm{gr} / \mathrm{cm}^{3}$, nilai ini jika dikategorikan pada tabel 14 termasuk kedalam jenis tanah gambut, dengan batasan 1,25-1,80. Dari hasil analisis dalam pengujian ini dikategorikan termasuk kedalam jenis tanah gambut dilihat dari klasifikasi tanah (Hardiyatmo, 1992).

f. Pengujian Kuat Geser ASTMD-3080

Tujuan pengujian kuat geser ini adalah merupakan salah satu metode yang dapat digunakan untuk menentukan kuat geser tanah dilaboratorium. Kuat geser tanah merupakan kemampuan tanah untuk menahan keruntuhan dan longsor dalam tanah, kuat geser yang dimiliki oleh suatu tanah dipengaruhi oleh, tanah berbutir halus (kohesi). Dari ketiga sampel tanah asli yang telah diuji mendapatkan nilai tegangan geser ratarata $0,453 \mathrm{~kg} / \mathrm{cm}^{2}, 0,389 \mathrm{~kg} / \mathrm{cm}^{2}$, dan $0,338 \mathrm{~kg} / \mathrm{cm}^{2}$. Dengan sudut geser dalam mendapatkan nilai $37,52^{\circ}$ dan nilai kohesi $0,14 \mathrm{~kg} / \mathrm{cm}^{2}$. Dari hasil pengujian kuat geser dengan campuran difa soil stabilizer dan semen untuk setiap sampel mendapatkan nilai :

Tabel 4. Rekapitulasi Kuat Geser Tanah + Difa SS + Semen

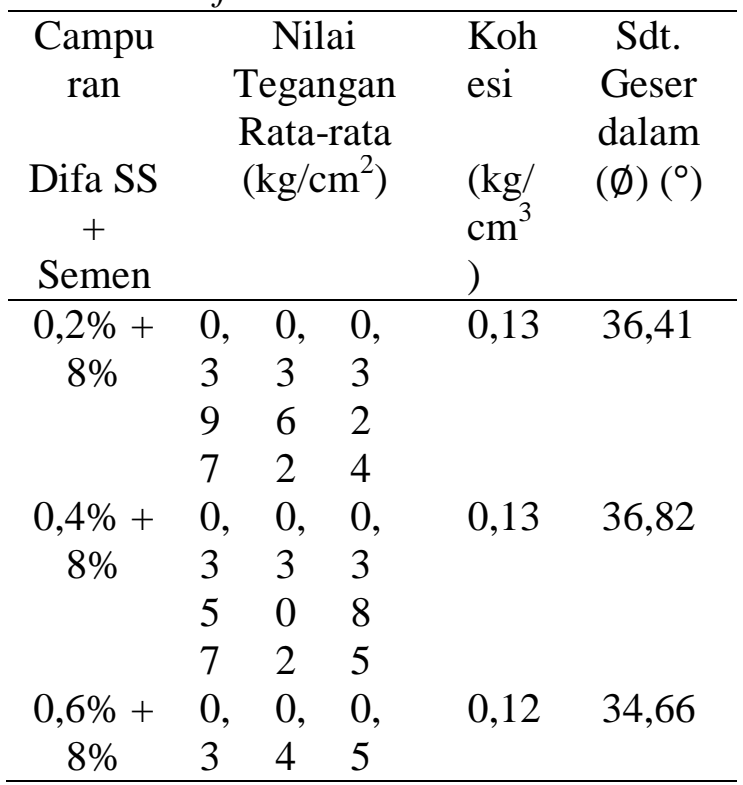

\begin{tabular}{cccccc}
\hline & 5 & 9 & 0 & & \\
$0,8 \%+$ & 7 & 5 & 5 & & \\
$8 \%$ & 0, & 0, & 0, & 0,11 & 32,94 \\
& 4 & 5 & 5 & & \\
& 3 & 4 & 2 & & \\
& 7 & 6 & 5 & & \\
\hline
\end{tabular}

(Hasil Pengujian Di Laboratorium, 2021)

Dari tabel di atas, semua pengujian kuat geser tanah campuran, nilai tegangan geser yang paling tinggi adalah $0,4 \%$, dengan semakin penambahan zat additive difa soil stablizer maka kadar optimum (OMC), nilai tegangan geser semakin menurun. Jadi kesimpulan pengujian kuat geser tanah campuran zat additive difa soil stabilizer $0,4 \%$ yang mendekati batas ambang maksimum.

\section{KESIMPULAN}

Berdasarkan hasil penelitian yang dilakukan pada sampel tanah maka dapat disimpulkan bahwa sampel tanah yang diberi penambahan zat additive berupa difa soil stabilizer dapat memperbaiki atau meningkatkan daya dukung sifat mekanis tanah asli. Nilai PI semakin menurun dan tingkat kepadatan semakin meningkat serta kuat geser tanah berkurang. Sedangkan untuk pengujian kuat geser tanah yang dilakukan di Laboratorium Teknik Sipil Universitas Muhammadiyah Metro, dari ke empat sampel yang telah diujikan dengan campuran zat additive difa soil stabilizer yakni $0,2 \%, 0,4 \%, 0,6 \%, 0,8 \%+8 \%$ semen dalam setiap pengujian kuat geser campuran. Dari ke empat pengujian nilai tegangan geser dengan campuran $0,4 \%$ difa soil stabilizer $+8 \%$ semen mendapat kadar campuran dengan nilai lebih maksimum yakni mendapatkan nilai kohesi $0,13 \mathrm{~kg} / \mathrm{cm}^{2}$, sedangkan untuk sudut geser dalam mendapatkan nilai $36,82^{\circ}$. Sedangkan hasil dari pengujian pemadatan tanah campuran zat additive difa soil stabilizer mendapatkan kadar campuran maksimum 0,8\% difa soil stabilizer $+8 \%$ semen dengan kadar air optimum $38,20 \%$, dengan berat kering 
maksimum $1,15 \mathrm{gr} / \mathrm{cm}^{3}$. Nilai berat isi kering maksimum $\left(\gamma_{\mathrm{dmak}}\right)$ cenderung semakin meningkat dari tanah aslinya, sedangkan kadar air optimum (OMC) selalu mengalami penurunan, ini dikarenakan semakin meningkatya persentase penambahan campuran zat additive difa soil stabilizer oleh sebab itu tanah semakin kekurangan air.

\section{DAFTAR PUSTAKA}

Amran Yusuf \& Surandono Agus. 2017. Analisa Daya Dukung Tanah (DDT) Pada Subgrade Tanah Dasar (Studi Kasus : Ruas Jalan Ki Hajar Dewantara, 38 b Banjar Rejo Lampung TimurBatas Kota Metro). TAPAK (Teknologi Aplikasi Konstruksi): Jurnal Program Studi Teknik Sipil Universitas Muhammadiyah Metro, Volume 7 Nomor 1. Hal 6-10

Amran Yusuf, Sari D. Utama. 2018. Analisa Perbaikan Sub Grade/TanahDasar

Menggunakan Bahan Tambahan Kapur Dan Abu Sekam Padi Pada Ruas Jalan Ki Hajar Dewantara, 38 B Banjar Rejo Lampung Timur-Batas Kota Metro. Tapak (Teknologi Aplikasi Kontruksi), 8(1), h. 1-8.

Amran Yusuf, Sadiya Rizqi. 2019. AnalisisPeningkatan Sifat Mekanis Tanah Dasar Menggunakan Campuran AbuLimbah Ampas Tebu dan Semen.Tapak (Teknologi Aplikasi Kontruksi), 9(1), h. 7483.

Ariyani Ninik,Nugroho A.C. 2007. Pengaruh Kapur dan Abu Sekam Padi Pada Nilai CBR Laboratorium Tanah Tras Dari Dusun Seropan Untuk Stabilitas Subgrade Timbunan.Majalah Ilmiah UKRIM, 12(1), h. 1-16
ASTM D 2487-66T. Standart Classification of Soil for Engineering

ASTM D 1883-87. California Bearing Ratio Soaked

ASTM D-698. Standart Test Methods for Compaction

Badan Standarisasi Nasional. 2015. Tata Cara Pengklasifikasian Tanah UntukKeperluan Teknik Dengan Sistem Klasifikasi Unifikasi Tanah. Jakarta.

Bowles. 1991. Usaha pemadatan untuk mempertinggi kerapatan dan pemampatan partikel

Das B.M. 1994. Mekanika Tanah 1 Prisip Rekayasa Geoteknis Jilid 1. Erlangga. Jakarta

Direktorat Jendral Bina Marga. 2018. Spesifikasi Umum 2018 Untuk Pekerjaan Konstruksi Jalan dan Jembatan.

Hardiyatmo Christady Hary. 2002, Mekanika Tanah I. Gajah Mada University Press, Yokyakarta.

Hardiyanto H. Christady. 2010. Stabilisasi Tanah Untuk Perkerasan Jalan.Gadjah Mada Unuversity Press. Yogyakarta.

PT. DifaMahakarya. Profile Product. Yogyakarta. 